\title{
Neural Network Based Fault Diagnosis of Three Phase Inverter Fed Vector Control Induction Motor
}

\author{
Bilal Djamal Eddine Cherif ${ }^{1 *}$, Azeddine Bendiabdellah¹, Mokhtar Bendjebbar ${ }^{1}$, Amina Tamer $^{1}$ \\ 1 Diagnosis Group, Laboratory LDEE, Electrical Engineering Faculty, University of Sciences and Technology of Oran, Bir El Djir, \\ P. O. B. 1505, El-Mnaouer, Oran 31000, Algeria \\ * Corresponding author, e-mail: cherif.doc84@gmail.com
}

Received: 03 May 2019, Accepted: 16 July 2019, Published online: 31 October 2019

\begin{abstract}
The paper investigates the detection and location of IGBT open-circuit faults in two-level inverter fed induction motor controlled by indirect vector control strategy. The investigation proposes two new approaches entirely based on the Artificial Neural Network (ANN) for the extraction of the exact fault angle corresponding to the IGBT switch open-circuit fault. The first approach (Approach1) based on the Clark currents transform calculates the average value of the Clark currents to find the exact fault angle $\theta$. The second approach (Approach2) based directly on the three-phase stator currents (without any transformation) calculates the average value of the threephase currents to determine the exact fault angle between the phases $\left(\theta_{a b^{\prime}} \theta_{b c^{\prime}} \theta_{c a}\right)$. The paper conducts also a comparative study between the two approaches to assess the merits of each one of them. Experimental work is conducted to illustrate the effectiveness of the techniques and validate the results obtained.
\end{abstract}

Keywords

vector control, open-circuit fault, detection, location, ANN

\section{Introduction}

Three-phase induction machines have been used more and more in recent years in applications requiring variable speed. The combination of static converters with induction motors has gradually replaced DC motors in many industrial applications for speed variation. The attraction for this type of motors is for its robustness, low cost and high performance that can be achieved through the development of electronic components for the implementation of sophisticated control laws. However, control algorithms can become completely inefficient for both the system and the environment when a failure occurs. For reasons of safety but also for economic reasons, it is necessary to control at all times the proper functioning of the motor. The increase in reliability, availability and dependability is currently one of the major concerns of manufacturers. In some complex systems, such as in aeronautics or nuclear power plants, the phase of detecting, locating and reconfiguring one or more faults is necessary but not sufficient to guarantee operational safety. Indeed, it is essential to modify the control law to ensure continuity of service and to maintain the minimum level of performance [1].
According to the existing literature, the most common and critical faults in the inverter mainly concern the semi-conductor switches (IGBT in our case). The internal faults of the IGBT semi-conductors of the inverter are estimated at $31 \%$. This percentage may be even larger if the faults due to the operating control are taken into account $[2,3]$.

Several researchers have studied the behavior of static power converters with internal failure, focusing particularly on the open-circuit fault of an IGBT switch. Such a fault can lead to secondary faults in other converter components that can result in high repair costs [2]. Authors [3, 4] propose the Park vector technique, the principle of this technique is based on the tracking of the current trajectory of Park $\left(i_{d}, i_{q}\right)$. In the healthy case, the trajectory takes a circle shape and in the case of an IGBT switch open-circuit fault, the circle becomes a semicircle. The position of this trajectory in the $(d, q)$ frame makes it possible to calculate the intervals of the angles of the fault to localize the faulty IGBT. Other researchers [5-8] have proposed the Park average current $\left(i_{\text {dmean }}, i_{\text {qmean }}\right)$ 
technique to calculate the exact open-circuit fault angle in order to identify the faulty IGBT switch. Authors [5, $9,10]$ have proposed the technique based on the spectral analysis of the stator currents. This technique is based on the study of the harmonic analysis of each phase current. The amplitude and argument of each harmonic can be used in detecting and localizing the faults. The analysis of the first harmonics shows that the difference between the healthy state and the open-circuit fault case lies in the zero-order harmonics which means the presence of the DC component in the signal. The argument of the harmonic zero with respect to the fundamental makes it possible to know the type of fault; on the other hand, the argument of this harmonic also makes it possible to know the faulty IGBT switch either the high or the lower one. The authors [11] combined normalized standard currents with additional diagnostic variables for one or more IGBT switch open-circuit faults. The diagnostic alarms were performed by the Boolean output signals. In the paper presented by [12], the same authors proposed another extension based on the use of fuzzy logic symptoms. The author [13] proposes the Clarke technique followed by the polarity of the trajectory slope in the $(\alpha, \beta)$ frame to identify the faulty IGBT switch.

This paper investigates the detection of open-circuit IGBT faults in inverters using the artificial intelligence technique; the Artificial Neural Network (ANN) for extracting the exact angles of the fault. Two approaches are employed; Approachlis related to the Clark currents transform for calculating the exact angle of the open-circuit fault. Approach 2 based on the calculation of the mean value of the three stator currents to determine the angles between phases $\left(\theta_{a b}, \theta_{b c}, \theta_{c a}\right)$. A comparison study between the two approaches is carried out. The experimental work performed is to evaluate the effectiveness of the two proposed new approaches and to validate the results obtained.

\section{Experimental setup descriptions}

The experimental test-rig used in this paper, includes a three-phase squirrel-cage induction motor fed by a three-phase two-level voltage source inverter. The detailed characteristics of the motor are given in the appendix. Furthermore, the motor is mechanically coupled to a dc generator supplying a bank of resistors which allows varying the load torque. Moreover, the measuring system includes three current Hall Effect sensors and three voltage sensors and a DSPACE 1104 acquisition card to generate pulses for triggering the IGBT's gates. The whole set is connected to a computer for visualizing the processed sensed signal as shown in the photo of Fig. 1 [14].

Given the randomness of the measured signals and in order to have a reliable analysis, 05 acquisitions are made for each case. The acquisition time used is $T_{a c q}=20 \mathrm{~s}$. It can also be noted that to study the effect of the load on the induction motor signals, only one mode of operation is considered: the rated load operation with a rated current of $7 \mathrm{~A}$ and an estimated torque of $20 \mathrm{Nm}$ and a frequency of sampling $\mathrm{Fe}=10 \mathrm{KHz}$.

\section{Induction motor vector control technique (IFOC)}

In the following, a study of the indirect vector control technique applied to both a healthy inverter and a faulty inverter (case of an IGBT open-circuit fault at switch $K_{1}$ ) is presented and investigated.

\subsection{Indirect vector control (IFOC) of a healthy inverter fed induction motor}

The purpose of the vector control is to be able to control the induction motor as a self-excited DC machine where there is a natural decoupling between the magnitude controlling the flux (the excitation current) and that related to the torque (the armature current). This decoupling makes it possible to obtain a very fast torque response [15-17]. The indirect vector control of a three-phase two-level inverter is illustrated by the synoptic diagram as shown in Fig. 2.

The vector control is that based on the orientation of the rotor flux. The $(d-q)$ axis system is oriented so that the axis $d$ is in phase with the rotor flux.

$\left\{\begin{array}{l}\varphi_{r d}=\varphi_{r} \\ \varphi_{r q}=0\end{array}\right.$

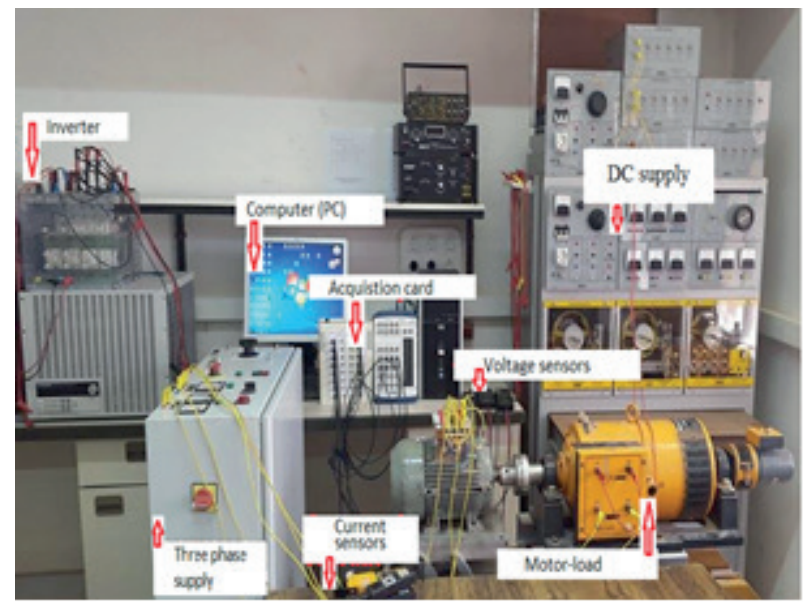

Fig. 1 Photo of the experimental test-rig [14]. 


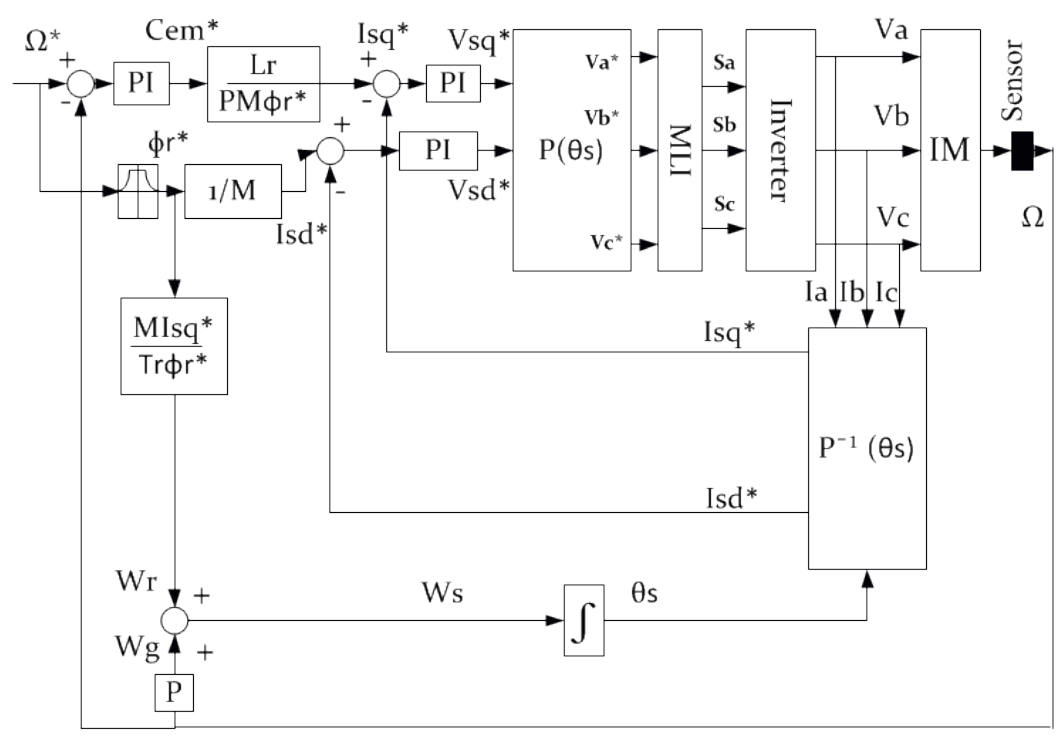

Fig. 2 IFOC technique of a healthy inverter fed induction motor.

The equations of the machine in a frame related to the rotating field become:

$$
\left\{\begin{array}{l}
i_{a s}=i \cos (\omega t+\varphi) \\
i_{b s}=i \cos \left(\omega t+\varphi-\frac{2 \pi}{3}\right) \\
i_{c s}=i \cos \left(\omega t+\varphi-\frac{4 \pi}{3}\right)
\end{array}\right.
$$

\section{- Stator side:}

$$
\left\{\begin{array}{l}
V_{s q}=R_{s} i_{s q}+\sigma L_{s} \frac{d i_{s q}}{d t}+\omega_{s} \frac{M}{L_{r}} \varphi_{r}-\omega_{s} \sigma L_{s} i_{s d} \\
V_{s d}=R_{s} i_{s d}+\sigma L_{s} \frac{d i_{s d}}{d t}+\frac{M}{L_{r}} \frac{d \varphi_{r}}{d t}-\omega_{s} \sigma L_{s} i_{s q}
\end{array}\right.
$$

\section{- Rotor side:}

$$
\begin{aligned}
& T_{r} \frac{d \varphi_{r d}}{d t}+\varphi_{r}=M i_{s d} \\
& \omega_{s l}=\omega_{s}-\omega_{r}=\frac{M}{T_{r}} \frac{i_{s q}}{\varphi_{r}} .
\end{aligned}
$$

The electromagnetic torque is reduced to:

$$
C_{e m}=p \frac{M}{L_{r}} \varphi_{r} i_{s q}
$$

\subsection{Indirect vector control (IFOC) of a faulty inverter fed induction motor}

The vector control is applied to an induction motor with an open-circuit fault at the IGBT switch $K_{1}$ of the inverter. This type of control consists in controlling the two healthy phases after the disconnection of the faulty phase. The references of the currents can be given by $[5,17,18]$ :

$$
\left\{\begin{array}{l}
i_{a s}=0 \\
i_{b s}=i \cos \left(\omega t+\varphi-\frac{2 \pi}{3}\right) \\
i_{c s}=i \cos \left(\omega t+\varphi-\frac{4 \pi}{3}\right)
\end{array}\right.
$$

The torque under the open-circuit fault condition is expressed by the following relation:

$C_{e m F}=\frac{6}{9} \frac{p M}{L_{r}} \varphi_{r} i_{s q}$.

Fig. 3 depicts the experimental results of the indirect vector control technique applied to a healthy inverter and a faulty inverter (case of an IGBT open-circuit fault at switch $K_{1}$ ).

Fig. 3 shows the behavior of the induction motor fed by both a healthy inverter and a faulty inverter for a speed reference during a load start. Note that for the case of the healthy inverter, the shape of the speed follows perfectly its reference without any overshoot which is reached very quickly. It can also be noticed small oscillations of the instantaneous torque during startup but for a very short time. It is clear that the performance of the speed regulation loop is satisfactory and its rise time is acceptable and even the rejection of the disturbance is ensured.

In the abnormal regime, the electrical quantities (the stator currents) are compared to the normal regime considered as the reference. Due to the sudden change in the current of phase A, characterized by the disappearance of the positive alternation at the instant of the $K_{1}$ 

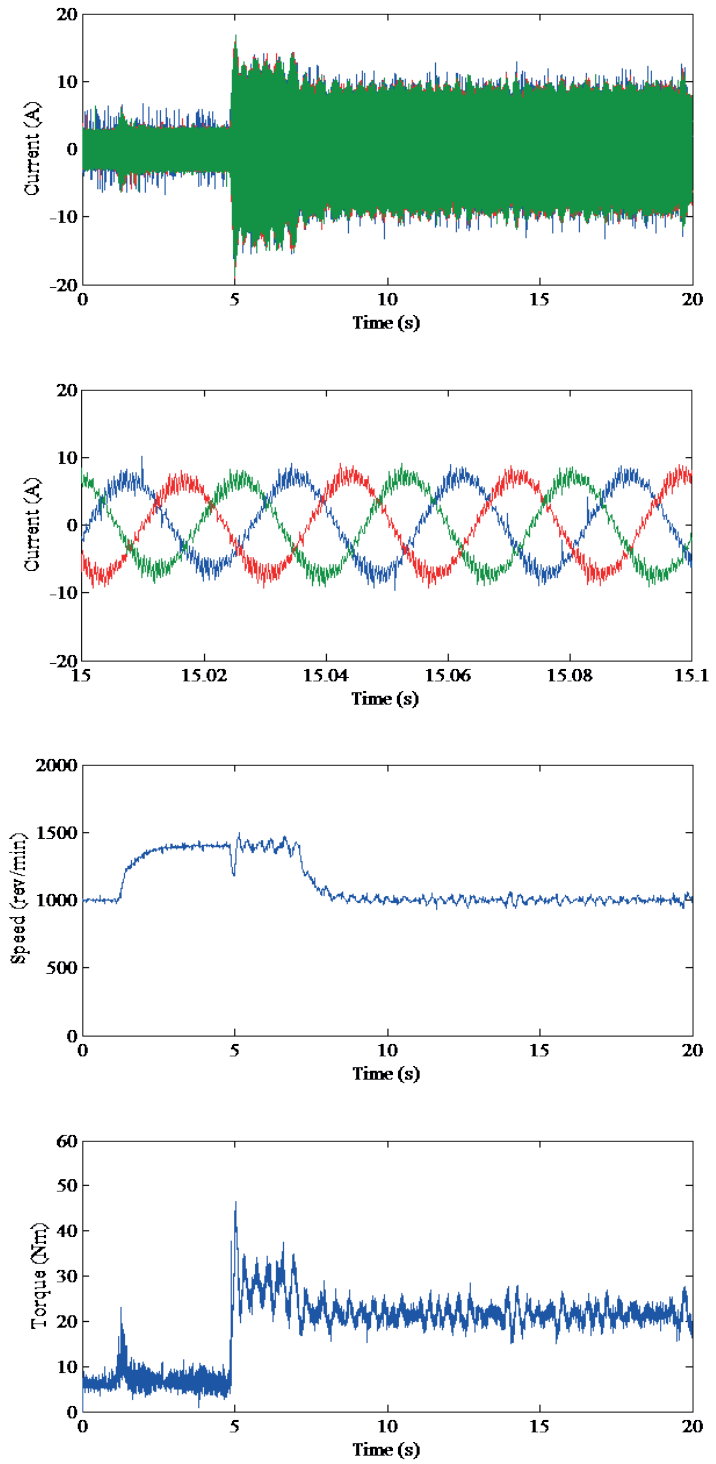

(a)
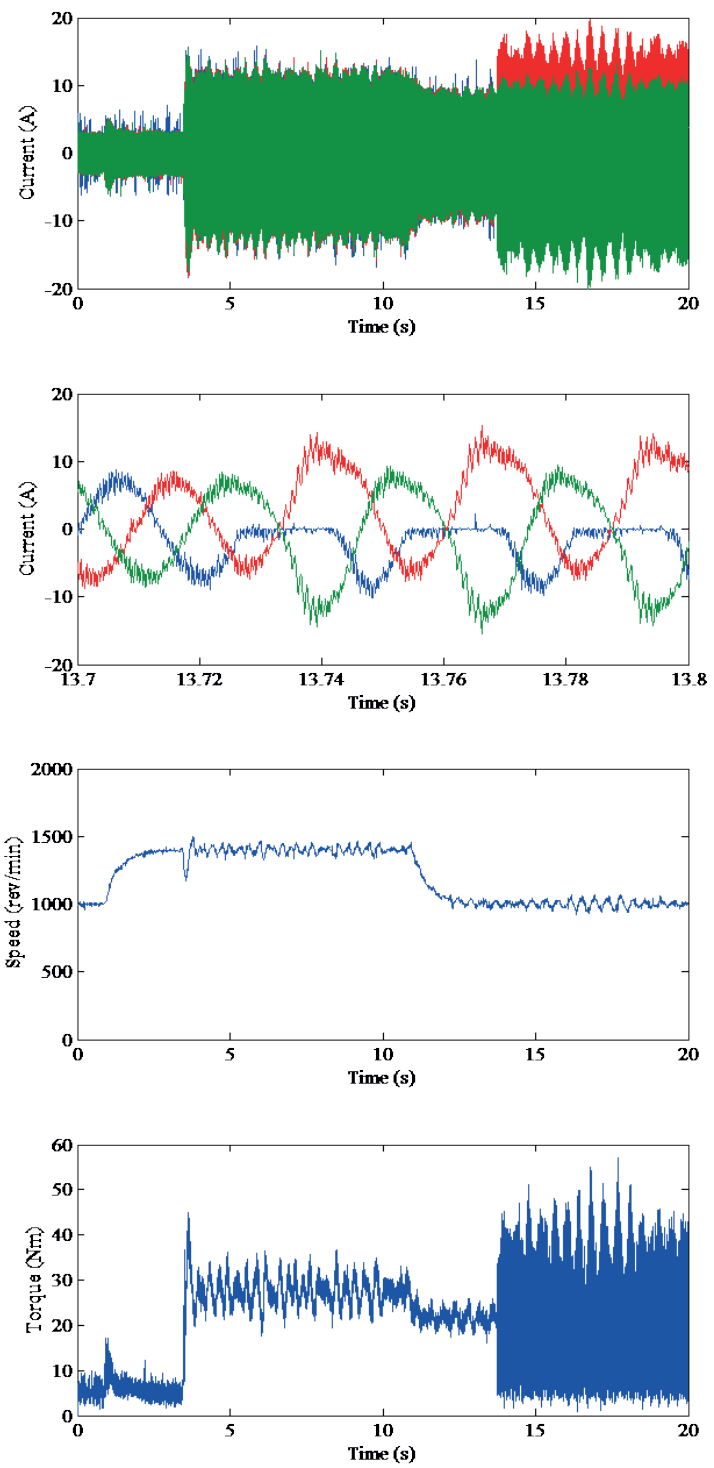

(b)

Fig. 3 Experimental results of the IFOC technique: (a) Vector control with a healthy inverter. (b) Vector control with a faulty inverter

IGBT switch open-circuit fault occurrence, the phase current connected to the faulty arm is no longer controlled as it is only negative or zero. Under these conditions the current of the other two healthy phases (zero sum) take instantaneously high values. Furthermore, it should also be noted that the IGBT fault influences the mechanical behavior of the motor. This influence is characterized by a fall in the speed value, as well as a variation (oscillations) of the electromagnetic torque resulting in a degraded operation of the motor.

\section{Inverter IGBT open-circuit fault detection techniques} The IGBT open-circuit fault detection techniques in this paper make use of the artificial neural network (ANN).
A presentation of this used ANN approach is therefore more than necessary.

\subsection{Principles of the used ANN}

The ANN structures used for the two approaches are illustrated in Fig. 4 and Fig. 5.

\subsection{ANN structure and training/test phase}

A very rich database is built for both healthy and faulty modes of operation. The dataset for training and test are obtained from real measurement system of current described in this article. The recorded data were divided in equal time $(1 \mathrm{~s})$ and pick up randomly for the training and the test. Finally, we get 7 types of dataset according to the healthy and faulty modes 
of operations. Each type is divided in two groups (15 sets for training and 5 sets for the test). The same database will be used for the two approaches; Approach1 related to the Clark currents transform for calculating the exact angle of

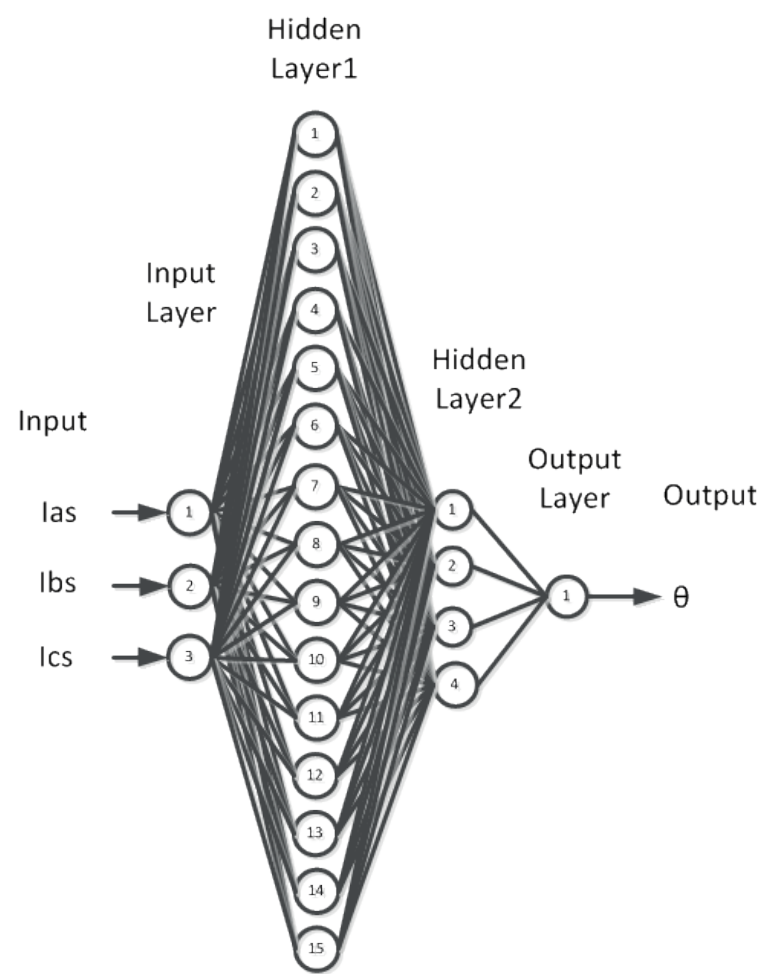

Fig. 4 ANN architecture for Approach1.

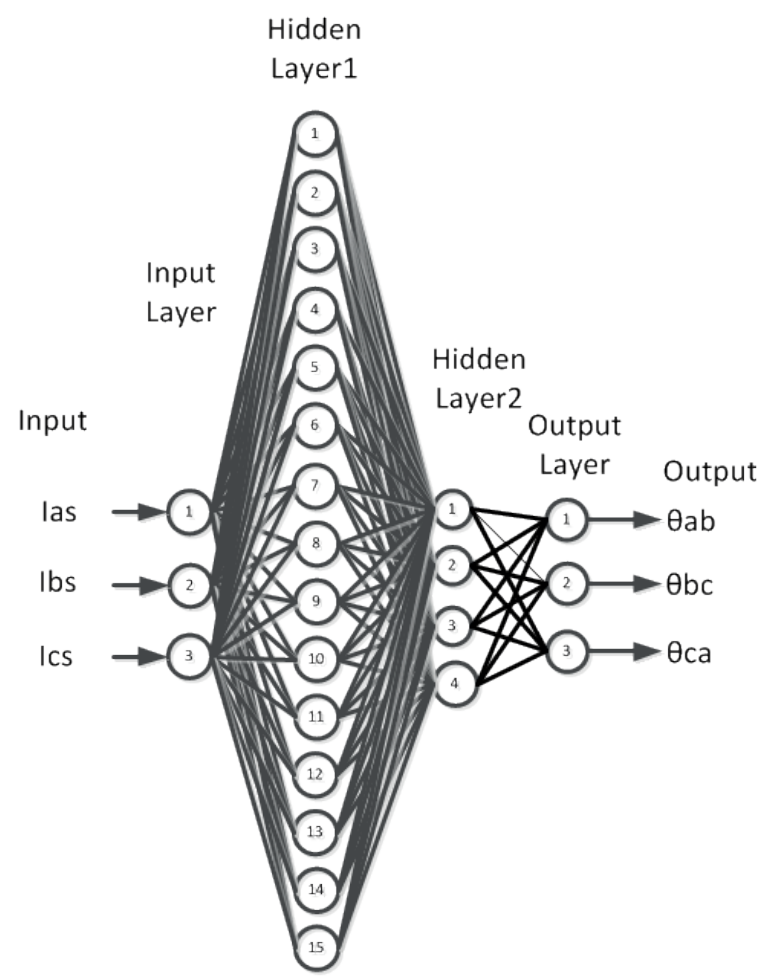

Fig. 5 ANN architecture for Approach2. the open-circuit fault, and the second Approach2 based on the calculation of the mean value of the three stator currents to determine the angles between phases $\left(\theta_{a b}, \theta_{b c}, \theta_{c a}\right)$.

The structure of the proposed ANN model is shown in Table 1. The network consists of four layers, an input layer with three (3) neurons corresponding to the current measured from sensors of the three phases $a, b$, and $c$ for the first approach, and $I_{\text {amean }}, I_{\text {bmean }}$ and $I_{\text {cmean }}$ for the second approach. $I_{\text {amean }}, I_{\text {bmean }}$ and $I_{\text {cmean }}$ were calculated from recorded data. The structure of the ANN changes according to the target; we get two structures, the first one with one (01) neuron in the output layer corresponding to the target $\theta$. The second structure will be with three (03) neurons in the output layer corresponding to $\left[\theta_{a b}, \theta_{b c}, \theta_{c a}\right]$ angles between phases. Finally, the hidden layer is the same for the both approaches, two (02) hidden layers with fifteen (15) neurons in the first layer and four (04) neurons in the second one. Fig.6 depicts the ANN proposed model

At the end of the training process, the model obtained consists of the optimal weight and the bias vector. The minimum performance gradient was set to $1 * 10^{-8}$ and training will stop when any one of these conditions is met:

1. The maximum number of epochs $=3297$.

2. The mean square error $=1.3294 * 10^{-9}$.

3. The performance gradient $<=1 * 10^{-9}$.

Table 1 Characteristics of the proposed ANN model.

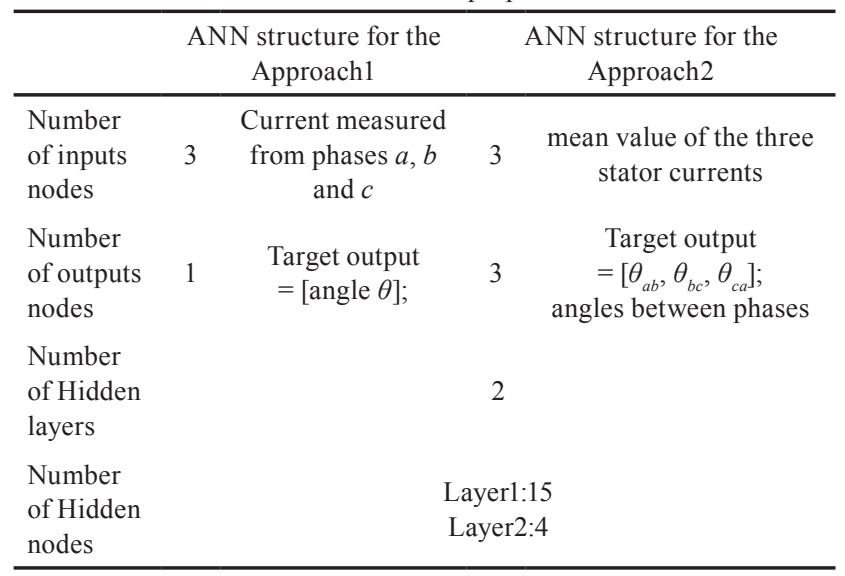

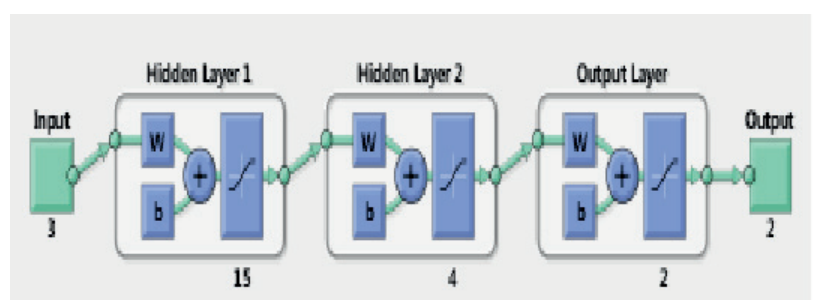

Fig. 6 ANN proposed model. 


\subsection{ANN test results}

An automatic learning of the ANN is performed until a small squared error of $1.3294 \mathrm{e}^{-09}$ is obtained, see Fig. 7. It should be noted that this small error is obtained after 3297 iterations.

\subsection{Approach1: extraction of the IGBT open-circuit fault angles based on ANN by the use of Clark transform approach}

In the following, the flowchart for Approach1 used to compute the exact fault angle extraction is presented in Fig. 8.

The mathematical model of Approach1 is presented by the following steps:

$\boldsymbol{I}^{\text {st }}$ step: Extraction of the three currents of the stator $\left(i_{a s}, i_{b s}, i_{c s}\right)$ as follows:

$$
\left\{\begin{array}{l}
i_{a s}=i \cos (\omega t+\varphi) \\
i_{b s}=i \cos \left(\omega t+\varphi-\frac{2 \pi}{3}\right) \\
i_{c s}=i \cos \left(\omega t+\varphi-\frac{4 \pi}{3}\right)
\end{array} .\right.
$$

$2^{\text {nd }}$ step: Calculation of the Clark currents:

$$
\left\{\begin{array}{l}
i_{\alpha s}=\frac{2}{3} i_{a s}-\frac{1}{3} i_{b s}-\frac{1}{3} i_{c s} \\
i_{\beta s}=\frac{1}{\sqrt{3}}\left(i_{b s}-i_{c s}\right)
\end{array} .\right.
$$

$3^{\text {rd }}$ step: Calculation of the intervals of the fault angles of each IGBT:

$$
\alpha=\tan ^{-1}\left(\frac{i_{\beta s}}{i_{\alpha s}}\right) .
$$

$4^{\text {th }}$ step: Calculation of the mean value of Clark currents:

$$
\left\{\begin{array}{l}
i_{\alpha \text { smean }}=\operatorname{sum}\left(\frac{i_{\alpha s}}{\operatorname{length}\left(i_{\alpha s}\right)}\right) \\
i_{\beta \text { smean }}=\operatorname{sum}\left(\frac{i_{\beta s}}{\operatorname{length}\left(i_{\beta s}\right)}\right)
\end{array}\right. \text {. }
$$

$5^{\text {th }}$ step: Calculation of the trajectory surface:

$$
S=S_{H}-S_{F} \text {. }
$$

Where $S_{H}$ and $S_{F}$ are the trajectory surfaces for healthy and faulty inverter cases respectively.

$\boldsymbol{6}^{\text {th }}$ step: Calculation of the exact angle of the open-circuit fault:

$$
\theta=\tan ^{-1}\left(\frac{i_{\beta \text { smean }}}{i_{\text {osmean }}}\right) \text {. }
$$

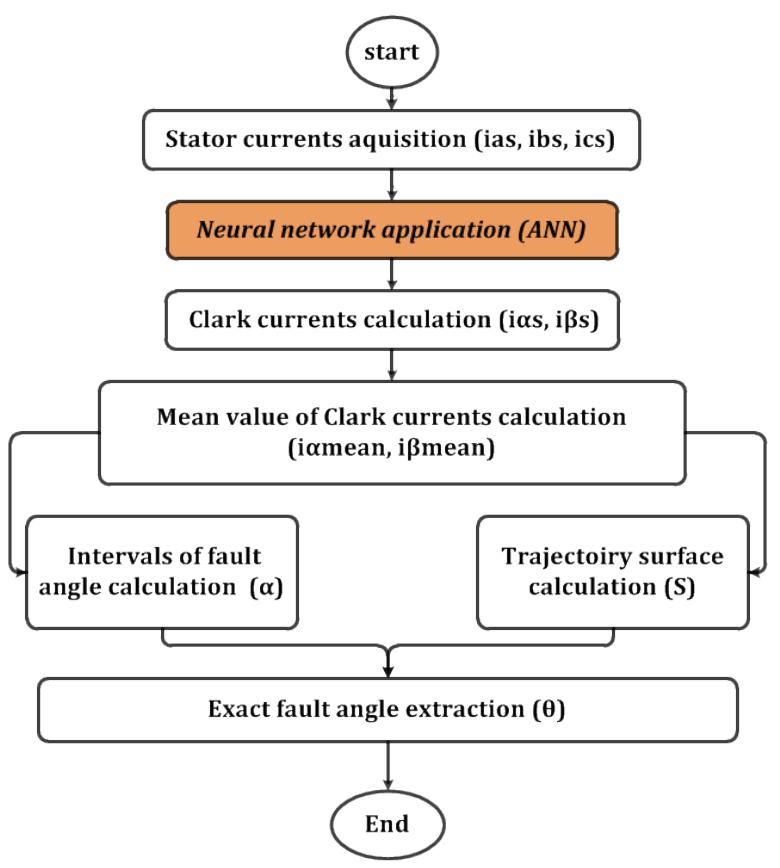

Fig. 8 Flowchart the ANN faults detection system (Approach1).

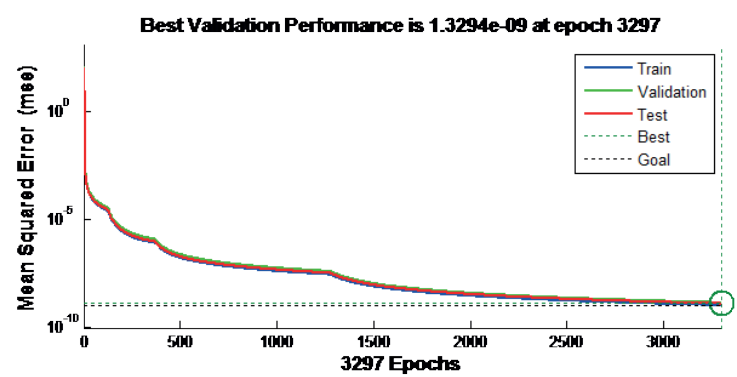

Fig. 7 Quadratic error evaluation as a learning iterations number function (gradient retro-propagation method).

Fig. 9 depicts the Clark current trajectories and the intervals of fault angles $\alpha$ for the healthy and faulty inverter case, with an open-circuit IGBT switch at $K_{1}$ and its complimentary $K_{2}$.

The information of each ANN output quantity for the healthy and faulty inverter cases are summarized in Table 2.

\subsection{Approach2: Extraction of the IGBT open-circuit} fault angles based on the ANN by the use of the three stator currents mean value approach

Fig. 10 presents the flowchart of Approach2 for the exact fault angles extraction

The mathematical model of Approach2 is presented by the following steps:

$1^{\text {st }}$ step: Extraction of the three currents of the stator $\left(i_{a s}\right.$, $\left.i_{b s}, i_{c s}\right)$ as follows: 

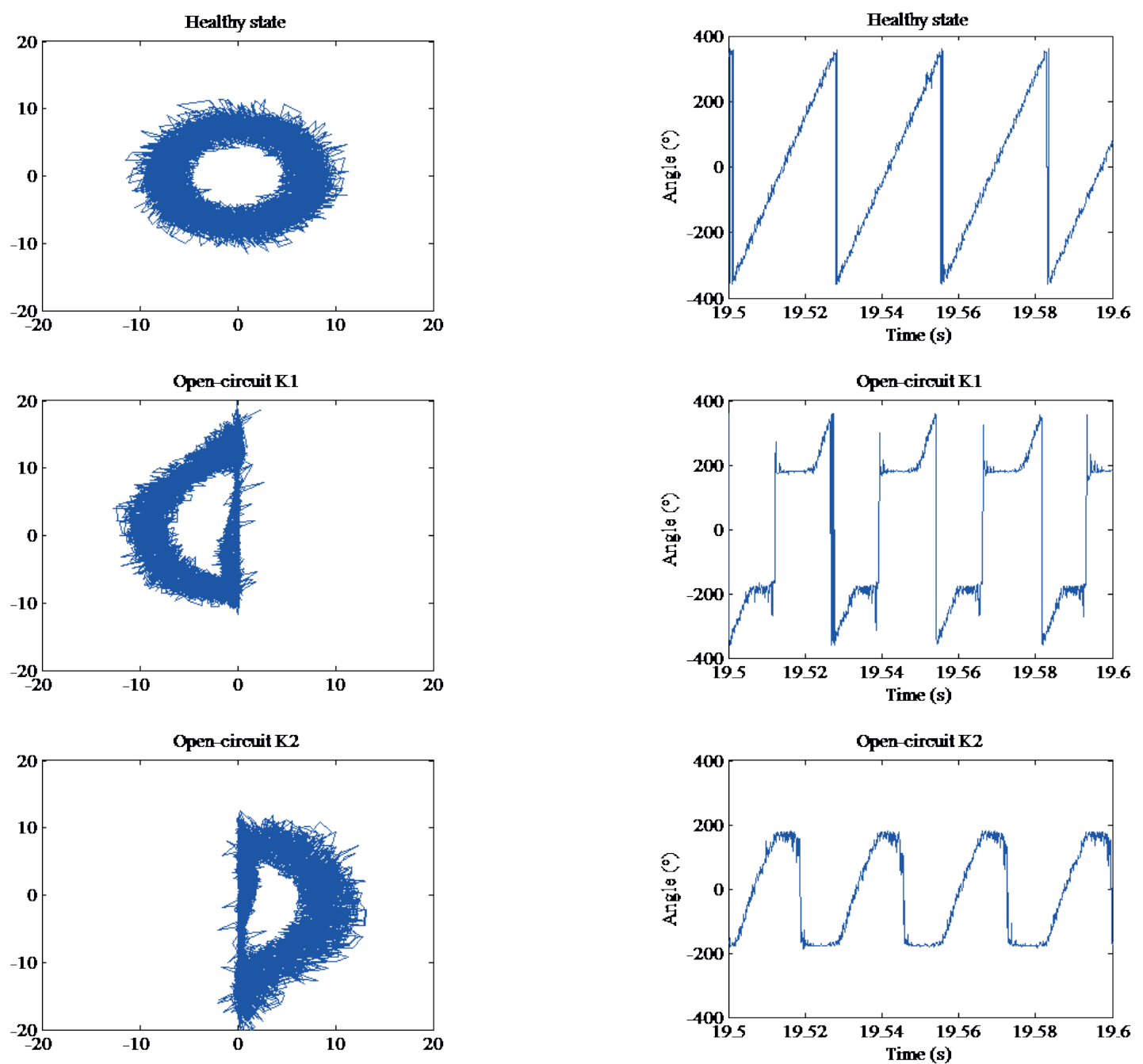

Fig. 9 Clark current trajectories and intervals of fault angles $\alpha$ for healthy and faulty inverter open-circuit $K_{1}$ and its complimentary $K_{2}$.

Table 2 Diagnostic characteristics by ANN based on Clark transform (first approach).

\begin{tabular}{lcccc}
\hline IGBT & \multicolumn{3}{c}{ The ANN outputs } \\
& $I_{\text {amean }}$ & $I_{\beta \text { mean }}$ & Angles intervals $\alpha\left(^{\circ}\right)$ & Surface $S$ \\
\hline Healthy case & 0.0274 & 0.0156 & {$[0,360]$} & $7.5688 \mathrm{e}^{-005}$ \\
Open-circuit $K_{1}$ & -5.7511 & 0.3127 & {$[150,210]$} & 7.8202 \\
Open-circuit $K_{2}$ & 5.4361 & -0.0361 & {$[330,30]$} & 7.6575 \\
Open-circuit $K_{3}$ & 1.3236 & -3.1518 & {$[270,330]$} & 7.7224 \\
Open-circuit $K_{4}$ & -1.3563 & 3.5092 & {$[90,150]$} & 7.5196 \\
Open-circuit $K_{5}$ & 1.3041 & 3.4924 & {$[30,90]$} & 7.6198 \\
Open-circuit $K_{6}$ & -1.5625 & -3.2893 & {$[210,270]$} & 7.2918 \\
\hline
\end{tabular}

$\left\{\begin{array}{l}i_{a s}=i \cos (\omega t+\varphi) \\ i_{b s}=i \cos \left(\omega t+\varphi-\frac{2 \pi}{3}\right) \\ i_{c s}=i \cos \left(\omega t+\varphi-\frac{4 \pi}{3}\right)\end{array}\right.$.

$2^{\text {nd }}$ step: Calculation of the mean value of the three sta-

$$
\left\{\begin{array}{l}
i_{a s}=\operatorname{sum}\left(\frac{i_{\alpha}}{\operatorname{length}\left(i_{\alpha}\right)}\right) \\
i_{b s}=\operatorname{sum}\left(\frac{i_{b}}{\operatorname{length}\left(i_{b}\right)}\right) \\
i_{c s}=\operatorname{sum}\left(\frac{i_{c}}{\operatorname{length}\left(i_{c}\right)}\right)
\end{array} .\right.
$$
tor currents: 


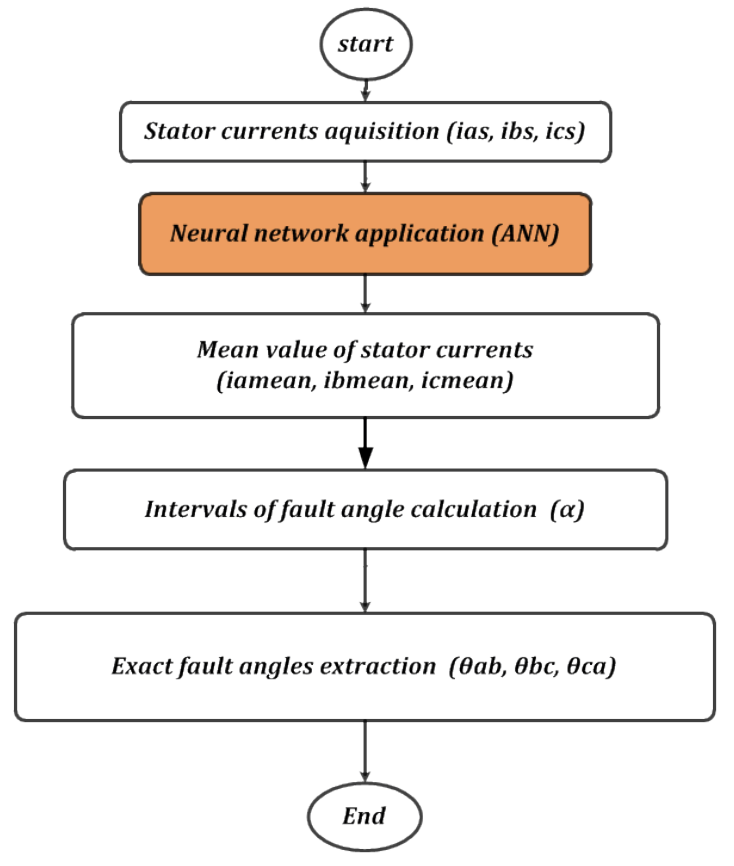

Fig. 10 Flowchart ANN faults detection system (Approach2).

$3^{\text {rd }}$ step: Calculation of the exact fault angles between phases of the open-circuit fault of each IGBT:

$\left\{\begin{array}{l}\theta_{a b}=\tan ^{-1}\left(\frac{I_{\text {bmean }}}{I_{\text {amean }}}\right) \\ \theta_{b c}=\tan ^{-1}\left(\frac{I_{\text {cmean }}}{I_{\text {bmean }}}\right) . \\ \theta_{c a}=\tan ^{-1}\left(\frac{I_{\text {amean }}}{I_{\text {cmean }}}\right)\end{array}\right.$

Fig. 11 depicts the stator currents trajectories and the intervals of fault angles $\alpha$ for the healthy and faulty inverter case open-circuit $K_{1}$ and its complimentary $K_{2}$.

The information of each ANN output quantity for the healthy and faulty cases is summarized in Table 3.

It is to conclude that the results obtained and summarized in Table 2 and Table 3 when applying the two approaches proposed for fault detection and location, indicate clearly that the exact open-circuit fault angles lay always within the intervals fault angles $\alpha$. By considering a study case example where the inverter IGBT switch open-circuit fault is supposed to occur at $K_{2}$, its fault angle interval $\alpha$ is found to lie within $\left[330^{\circ}, 30^{\circ}\right]$. It is to note that for Approach1, the given open-circuit fault at $K_{2}$ is identified by a single exact fault angle whose value is equal to $\theta=359.6198^{\circ}$. However, for the Approach2, the fault at $K_{2}$ is identified by no less than three different exact fault angles whose values are equal to $\theta_{a b}=346.0386^{\circ}, \theta_{b c}=227.7555^{\circ}$ and $\theta_{c a}=12.7230^{\circ}$. From these findings it can be deduced that the detection and location of the fault can be obtained from one of the two proposed approaches but Approach2 offers a supplementary advantage related to the fact that the detection and the location of the fault is identified and confirmed each time by three exact fault angles at the same time making it a sure and more reliable tool than Approach1.

Fig. 12 depicts a graphical representation related to Table 2 and Table 3 for the calculation of the fault angles by both approaches; the Clark currents transform and the three-phase stator mean currents approaches.

As it can be seen from Fig. 12, for the case of the IGBT switch $K_{2}$ open-circuit fault, It can be noticed for Approach2 that three vectors related to the three exact fault angles corresponding to the faulty inverter IGBT switch are in the range of the interval fault angle $\alpha$, whereas for Approach1, one single vector related to the exact fault angle lies within the fault interval angle $\alpha$.

\section{Comparative study between the two proposed approaches}

It can be deduced from the various tests of the $\mathrm{ANN}$, that the mean value of the three stator currents using Approach2 has some advantages compared to that of the mean value of the Clark currents transform using Approach1 detection

Table 3 Diagnostic characteristics by ANN based on the three stator currents (Approach2).

\begin{tabular}{|c|c|c|c|c|c|c|c|}
\hline \multirow{3}{*}{ IGBT } & \multicolumn{7}{|c|}{ The ANN outputs } \\
\hline & \multirow{2}{*}{$I_{\text {amean }}$} & \multirow{2}{*}{$I_{\text {bmean }}$} & \multirow{2}{*}{$I_{\text {cmean }}$} & \multirow{2}{*}{ Fault angles intervals $\alpha\left(^{\circ}\right)$} & \multicolumn{3}{|c|}{ Exact fault angles } \\
\hline & & & & & $\theta_{a b}\left({ }^{\circ}\right)$ & $\theta_{b c}\left({ }^{\circ}\right)$ & $\theta_{c a}\left({ }^{\circ}\right)$ \\
\hline Healthy state & 0.0247 & -0.0044 & 0.0061 & {$[0,360]$} & -10.1773 & -35.9173 & -13.9197 \\
\hline Open-circuit $K_{1}$ & -5.5271 & 1.3515 & 1.2621 & {$[150,210]$} & 166.2600 & 46.9587 & 192.8625 \\
\hline Open-circuit $K_{2}$ & 5.5391 & -1.3771 & -1.2506 & {$[330,30]$} & 346.0386 & 227.7555 & 12.7230 \\
\hline Open-circuit $K_{3}$ & 1.2391 & -5.5508 & 1.3976 & {$[270,330]$} & 282.5838 & 284.1322 & 311.5604 \\
\hline Open-circuit $K_{4}$ & -1.2195 & 5.5329 & -1.3810 & {$[90,150]$} & 102.4296 & 104.0144 & 131.4463 \\
\hline Open-circuit $K_{5}$ & 1.3826 & 1.2727 & -5.5594 & {$[30,90]$} & 42.6307 & 167.1057 & 76.0346 \\
\hline Open-circuit $K_{6}$ & -1.3861 & -1.2584 & 5.5326 & {$[210,270]$} & 222.2356 & 347.1861 & 255.9352 \\
\hline
\end{tabular}



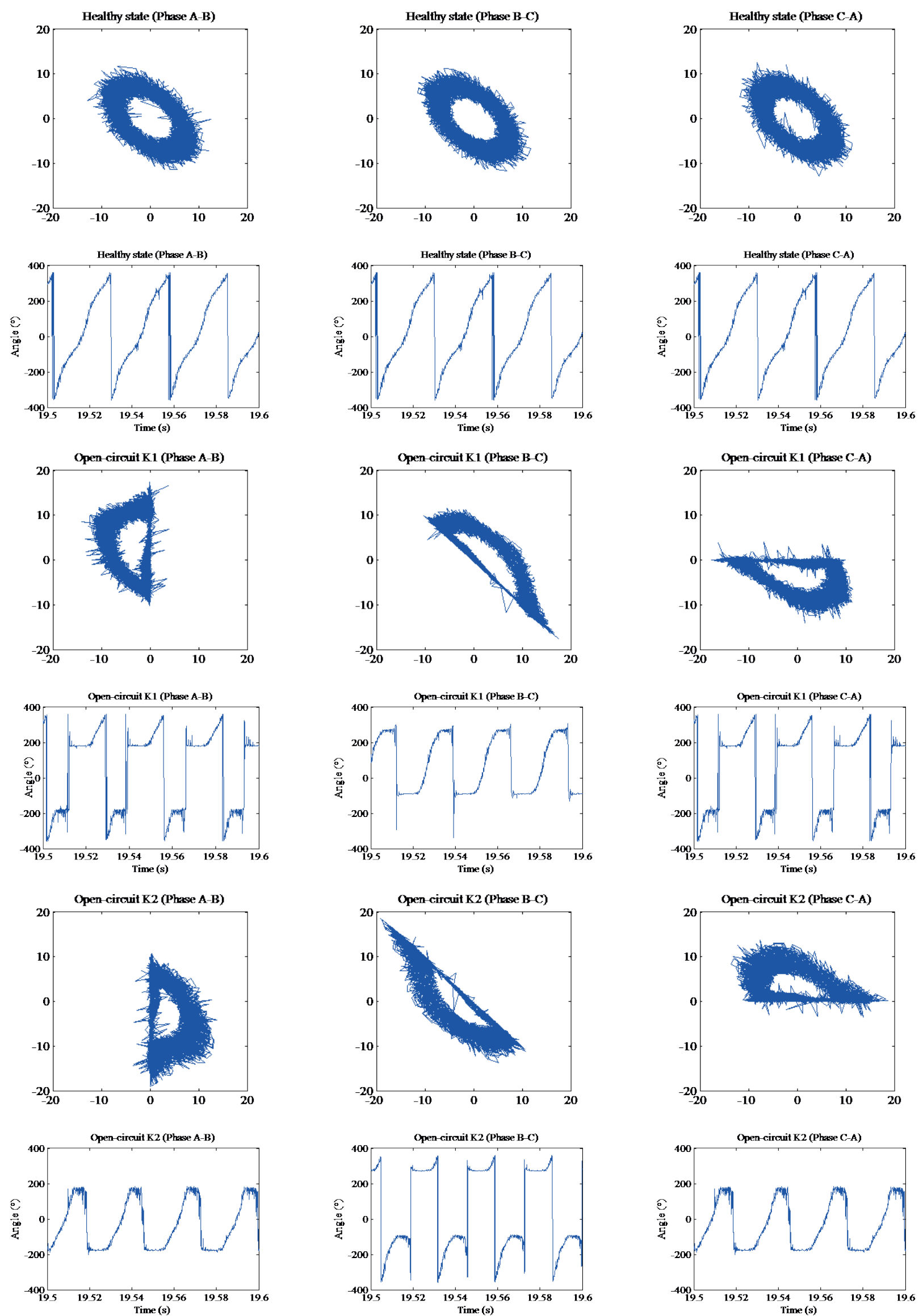

Fig. 11 Stator current trajectories and intervals fault angles $\alpha$ for healthy and faulty inverter open-circuit $K_{1}$ and its complimentary $K_{2}$. 


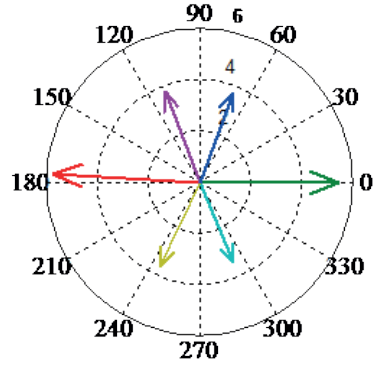

(a)

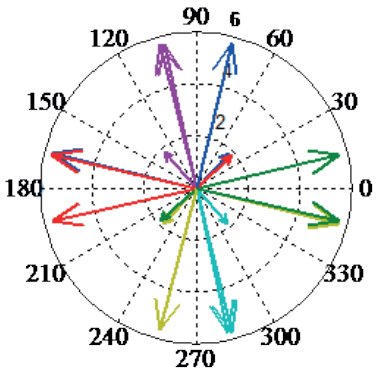

(b)

Fig. 12 Exact fault angles calculation of each approach based on the ANN. (a) Clark currents transform (Approach1)

(b) Three stator mean currents (Approach2)

Table 4 Comparative study between proposed Approach1 and Approach2

\begin{tabular}{lccc}
\hline Techniques & ANN structure & $\begin{array}{c}\text { ANN execution time for } \\
\text { output loop calculation } \\
(\mathrm{ms})\end{array}$ & $\begin{array}{c}\text { Open-circuit fault } \\
\text { detection time (ms) }\end{array}$ \\
\hline $\begin{array}{l}\text { Clark currents transform } \\
\text { (Approach1) }\end{array}$ & $(3-15-4-1)$ & 1.1829 & 5 \\
$\begin{array}{l}\text { Three stator currents } \\
\text { (Approach2) }\end{array}$ & $(3-15-4-3)$ & 0.7528 & 6 \\
loops required for fault & & 3 \\
\hline
\end{tabular}

time of $5 \mathrm{~ms}$ in comparison to the fast detection time of $2.5 \mathrm{~ms}$ obtained for Approach2. The reason is related to the number of calculating loops required for the computation of the extraction of the exact open-circuit fault angle in each approach as indicated in Table 4. From the information in Table 4, Approach1 indicates a slow.

\section{Conclusions}

The present paper addresses a performance comparative study of two proposed new approaches for the diagnosis of a two-level three-phase voltage inverter feeding an induction motor controlled by an indirect vector control strategy. The characteristics of the used ANN play a vital role for detecting and locating the IGBT switch open-circuit fault in both proposed approaches with simple calculations.

Several ANN tests of the healthy inverter and the faulty inverter are conducted. The experimental results obtained for the two diagnostic proposed approaches are

\section{References}

[1] Cherif, B. D. E., Bendiabdellah, A., Khelif, M. A. "Detection of Open-Circuit Fault in a Three-Phase Voltage Inverter Fed Induction Motor", International Review of Automatic Control, 9(6), pp. 374-382, 2016.

https://doi.org/10.15866/ireaco.v9i6.10268

[2] Cherif, B. D. E., Bendiabdellah, A., Khelif, M. A., Bendjebbar, M., Benouzza, N. "The enhancement of park current vectors technique for inverter fault detection", In: 2017 6th International Conference on Systems and Control (ISCS), Batna, Algeria, 2017, pp. 377-382. https://doi.org/10.1109/ICoSC.2017.7958646 discussed and the characteristics of each approach are thoroughly illustrated. These characteristics are used to compare the identification response of the fault angles. The set of the ANN tests performed presents globally satisfactorily performances in the case of the open-circuit fault of each IGBT. It is to note that the ANN open-circuit fault identification of each approach is performed more than 30 times for information extraction.

As it can be deduced from the comparative Table 4, not only Approach2 can detect the inverter IGBT switch open-circuit fault with more reliability and ensured way but also with a faster detection time of $2.5 \mathrm{~ms}$ compared to Approach1 where the detection time is rather slow equals to $5 \mathrm{~ms}$.

Finally to assess the effectiveness of both proposed approaches and validate the obtained results, experimental tests conducted in the LDEE laboratory by the diagnostic group are presented and discussed.

[3] Orlowska-Kowalska, T., Sobanski, P. "Simple diagnostic technique of a single IGBT open-circuit faults for a SVM-VSI vector controlled induction motor drive", Bulletin of the Polish Academy of Sciences-Technical Sciences, 63(1), pp. 281-288, 2015. https://doi.org/10.1515/bpasts-2015-0032

[4] Cherif, B. D. E., Bendiabdellah, A., Bendjebbar, M., Telli, A. "A comparative study between methods of detection and localisation of open-circuit faults in a three phase voltage inverter fed induction motor", International Journal of Modelling, Identification and Control, 29(4), pp. 327-340, 2018. https://doi.org/10.1504/IJMIC.2018.10013129 
[5] Zhang, W., Xu, D., Enjeti, P. N., Li, H., Hawke, J. T, Krishnamoorthy, H. S. "Survey on Fault-Tolerant Techniques for Power Electronic Converters", IEEE Transactions on Power Electronics, 29(12), pp. 6319-6331, 2014.

https://doi.org/10.1109/TPEL.2014.2304561

[6] Orlowska-Kowalska, T., Sobanski, P. "Simple sensorless diagnosis method for open-switch faults in SVM-VSI-fed induction motor drive", In: IECON 2013 - 39th Annual Conference of the IEEE Industrial Electronics Society, Vienna, Austria, 2013, pp. 8210-8215. https://doi.org/10.1109/IECON.2013.6700507

[7] Asghar, F., Talha, M., Kim, S. H. "Comparative Study of Three Fault Diagnostic Methods for Three Phase Inverter with Induction Motor", International Journal of Fuzzy Logic and Intelligent Systems, 17(4), pp. 245-256, 2017. https://doi.org/10.5391/IJFIS.2017.17.4.245

[8] Jlassi, I., Khojet, S., Khil, E. "A MRAS-Luenberger Observer Based Fault Tolerant Control of PMSM Drive", Journal of Electrical Systems 10(1), pp. 48-62, 2014.

[9] Cherif, B. D. E., Bendjebbar, M., Bendiabdellah, A. "Diagnosis of open-circuit fault in a three phase voltage inverter fed induction motor", In: 2015 4th International Conference on Electrical Engineering (ICEE), Boumerdes, Algeria, 2015, pp. 1-4. https://doi.org/10.1109/INTEE.2015.7416736

[10] Estima, J. O., Freire, N. M. A., Marques Cardoso, A. J. "Recent advances in fault diagnosis by Park's vector approach", In: 2013 IEEE Workshop on Electrical Machines Design, Control and Diagnosis (WEMDCD), Paris, France, 2013, pp. 279-288. https://doi.org/10.1109/WEMDCD.2013.6525187

[11] Mendes, A. M. S., Cardoso, A. J. M. "Fault diagnosis in a rectifier-inverter system used in variable speed ac drives by the average current Park's vector approach", In: EPE'99, 8th European Conference on Power Electronics and Applications, Lausanne, Switzerland, 1999, pp. 1-9.

[12] Abramik, S., Sleszynski, W., Nieznanski, J., Piquet, H. "A diagnostic method for on-line fault detection and localization in VSI-fed ac drives", In: 10th European Conference on Power Electronics and Applications, Toulouse, France, 2003, pp. 2-4.
[13] Rothenhagen, K., Fuchs, F, W. "Performance of diagnosis methods for IGBT open circuit faults in voltage source active rectifiers", In: 2005 European Conference on Power Electronics and Applications, Dresden, Germany, 2005, pp. 4348-4354. https://doi.org/10.1109/EPE.2005.219426

[14] Cherif, B. D. E., Bendiabdellah, A. "Detection of Two-Level Inverter Open-Circuit Fault Using a Combined DWT-NN Approach", Journal of Control Science and Engineering, 2018, Article ID: 1976836, 2018. https://oi.org/10.1155/2018/1976836

[15] Raisemche, A., Boukhnifer, M., Larouci, C., Diallo, D. "Two Active Fault Tolerant Control Schemes of Induction Motor Drive in EV or HEV", IEEE Transactions on Vehicular Technology, 63(1), pp. 19-29, 2014. https://doi.org/10.1109/TVT.2013.2272182

[16] Benzineb, O., Tadjine, M., Benbouzid, M., Diallo, D. "Sur la commande tolérante aux défauts des machines asynchrones: Une approche implicite" (On the Fault Tolerant Control of Asynchronous Machines: An Implicit Approach), European Journal of Electrical Engineering, 15(6), pp. 633-658, 2013. (in French) https://doi.org/10.3166/ejee.15.633-657

[17] Jannati, M., Idris, N. R. N., Salam, Z. "A new method for modeling and vector control of unbalanced induction motors" In: 2012 IEEE Energy Conversion Congress and Exposition (ECCE), Raleigh, NC, USA, 2012, pp. 3625-3632. https://doi.org/10.1109/ECCE.2012.6342483

[18] Campos-Delgado, D. U., Espinosa-Trejo, D. R., Palacios, E. "Faulttolerant control in variable speed drives: a survey", IET Electric Power Applications, 2(2), pp. 121-134, 2008. https://doi.org/10.1049/iet-epa:20070203 